\title{
Body composition in relation to economic status among adult females
}

PRIYANKA SINGHAL AND RITA SINGH RAGHUVANSHI

Received: 16.12.2013; Revised: 05.09.2014; Accepted: 19.09.2014

See end of the paper for authors' affiliations PRIYANKA SINGHAL

Department of Foods and Nutrition, College of Home Science, G.B. Pant University of Agriculture and Technology, PANTNAGAR (UTTARAKHAND) INDIA

Email: psinghal160@gmail.com
ABSTRACT : This cross-sectional nature of research investigation consists of assessing nutritional status and body composition of 629 young women in the age range of 18-28 years. Mean BMI and waist hip ratio was revealed $20.3 \pm 3.4$ and $0.83 \pm 0.05$, respectively. Fat per cent showed an increasing trend in accordance with income slab. A decreasing trend was observed for fat free mass (\%) and total body water $(\%)$ in relation to income range. Mean observations for fat $(\%)$ have been found to be $21.27 \pm 6.55$, $22.74 \pm 6.77$ and $23.91 \pm 6.86$ at three corresponding income ranges. FFM $(\%)$ and fat (\%) had significant difference $(\mathrm{p}<0.01)$ at 1 per cent level for the groups viz., low income group-middle income group and middle income group-high income group. Anthropometric characteristics such as weight, BMI, waist circumference, hip circumference, triceps, biceps, sub-scapular and sum of skin fold thickness had rising trend with advancing income ranges while height, MUAC, WHR and supra-iliac revealed no such trend. Waist circumference showed to have significant difference $(\mathrm{p}<0.05)$ at 5 per cent level for the groups viz., low income group-middle income group and low income group-high income group. Waist hip ratio revealed significant difference $(\mathrm{p}<0.05)$ at 5 per cent level for the group low income group-middle income group.

KEY WORDS: Nutritional status, Body composition, Economic status, Adult females

— HOW TO CITE THIS PAPER : Singhal, Priyanka and Raghuvanshi, Rita Singh (2014). Body composition in relation to economic status among adult females. Asian J. Home Sci., 9 (2) : 357-362. 